\title{
Más allá del fundamento y la verdad. La inmanencia
}

\section{Beyond the Foundation and Truth. The Immanence}

\author{
Juan Pablo E. Esperón \\ Universidad Nacional de la Matanza \\ jpesperon@hotmail.com
}

\section{Resumen:}

En el presente artículo nos proponemos delimitar la cuestión del fundamento y la verdad en la tradición filosófica occidental a partir de preguntarnos ¿qué son y cómo se constituyen tanto el fundamento como la verdad?, tomando como eje la lectura heideggeriana sobre el tema. Luego relevamos algunas conexiones de la recepción deleuziana de la filosofía de Nietzsche expuesta en su libro Nietzsche y la filosofía para mostrar cómo Deleuze lucha y dirige un ataque decisivo contra el problema del fundamento y la verdad, cuestiones propias de la tradición filosófica cuyo recorrido le exige, a Deleuze, liberar al ser de aquellas ataduras, repensando nociones claves de la filosofía nietzscheana como fuerza, devenir, voluntad, eterno retorno y diferencia.

Palabras clave: fuerza, devenir, voluntad, eterno retorno, diferencia.

\begin{abstract}
:
In this paper we intend to define the question of foundation and truth in Western philosophical tradition by asking what foundation and truth are and how do they constitute themselves, adopting the Heideggerian reading on the subject, and then taking on some connections of the Deleuzian reception of Nietzsche's philosophy exposed on Nietzsche and Philosophy. This will show how Deleuze directs a decisive attack against the problem of the foundation and truth. These are specific issues of the philosophical tradition whose route requires, for Deleuze, to liberate the being from those bonds, rethinking key concepts of the Nietzschean philosophy, such as: force, becoming, will, eternal return and difference.
\end{abstract}

Keywords: Force, Becoming, Will, Eternal Return, Difference. 


\section{Introducción}

Según Heidegger, la metafísica occidental se constituye y se caracteriza, desde su comienzo histórico, por estar determinada desde una estructura de pensamiento cuyo carácter es la oposición disyuntiva exclusiva ${ }^{1}$ que presupone la lógica de la identidad. Dicha estructura está constituida por polos que se oponen entre sí para, luego, fundamentar la reducción de uno a otro. Ello pone en marcha a la metafísica misma y a la propia historia de Occidente, dado que, tal estructura de oposición que fue instituida por Platón al establecer dos realidades opuestas en donde una funciona como fundamento de la otra, y donde la verdad opera del lado del fundamento en detrimento del otro, termina por adoptarse en toda la historia de la metafísica, elaborando de la misma manera y bajo la misma lógica la reducción, a saber: de lo múltiple a lo uno (Antigüedad griega), de las creaturas al creador (Medioevo), y de lo representado a la representación (Modernidad). Ello, a su vez, muestra ciertos límites tanto del fundamento como de la verdad para la comprensión de la realidad que creemos deben ser puestos en cuestión y discutidos. Exponemos, a continuación, esta problemática y, por otro lado, abordamos una posición alternativa al planteo de la tradición filosófica a partir de la recepción deleuziana del pensamiento de Nietzsche. En Deleuze hemos encontrado una lucha feroz por liberar al pensamiento de toda lógica de reducción y oposición dualista o binaria que rige la tradición filosófica occidental, que justamente limita la actividad del pensar ${ }^{2}$ ya que que en esta tradición el pensamiento siempre debe encontrar aquel fundamento absoluto que justifique lo ente en general y a sí mismo. Deleuze pone todo su esfuerzo en elaborar una ontología del devenir; esto significa que en la filosofía deleuziana se muestra una liberación y un desarraigo del ser en su condición y estatus de fundamento de lo ente, que conlleva subsumir al ser en el devenir. Así, Deleuze logra mostrar que la realidad del ser es diferir y no fundamentar.

Por ende, planteado este escenario, en el presente artículo nos proponemos delimitar la cuestión del fundamento y la verdad en la tradición filosófica occidental a partir de preguntarnos qué son y cómo se constituyen tanto el fundamento como la verdad, tomando como eje la lectura heideggeriana sobre el tema. Luego relevamos algunas conexiones de la recepción deleuziana de la filosofía de Nietzsche, expuesta en su libro Nietzsche y la filosofía (Deleuze), para mostrar cómo Deleuze lucha y dirige un ataque decisivo contra el problema del fundamento y la verdad, cuestiones propias de la tradición filosófica cuyo recorrido le exige, a Deleuze, liberar al ser de aquellas ataduras, repensando nociones clave de la filosofía nietzscheana como fuerza, devenir, voluntad, eterno retorno y diferencia.

1 Una proposición disyuntiva tiene la forma: “O bien... o bien...”. Solo puede ser verdadera una de las dos alternativas de la disyunción, pero no ambas. Este mecanismo permite delimitar las identidades, excluyendo las diferencias.

2 Recordemos que en la filosofía deleuziana pensar debe comprenderse como crear y experimentar, y no como justificar o fundamentar, al modo de la tradición metafísica. 


\section{El problema del fundamento, la verdad y sus límites en la tradi- ción filosófica occidental a partir de la lectura heideggeriana}

\section{A. La disolución de la filosofía en metafísica y su identificación con la historia occidental en el pensamiento de Martin Heidegger}

Desde su inicio, la filosofía nace ligada a un forma de pensamiento de índole especulativo que impulsa la búsqueda de un fundamento o principio absoluto (arkhé) ${ }^{3}$ que permita explicar por qué son las cosas (fundamentar su existencia) y qué son las cosas (qué es lo que hace que los entes sean, su esencia), produciendo, disponiendo y determinando, al mismo tiempo, un tipo de discurso (lógos) ${ }^{4}$ de aquello pensado y fundamentado que podemos expresar en la estructura de la proposición lógica del lenguaje S es $\mathrm{P},{ }^{5}$ cuya nota distintiva es el acercamiento a la verdad. Es sabido que los pensadores que iniciaron la filosofía han especulado en este sentido ${ }^{6}$. Así, los primeros filósofos que indagaron por el fundamento de los entes naturales, entre ellos Tales, Anaxímenes y Anaximandro han hallado (intuido), como sustrato de la realidad, un ente material (el agua, lo indeterminado o el aire) y, de ello se infiere, la reducción de la multiplicidad de entes a un fundamento único. En contraposición, los pitagóricos, Sócrates y Platón han tomado un aspecto formal y abstracto para explicar la realidad, respondiendo a la pregunta por el fundamento con la cifra, el concepto y la idea, respectivamente. Sin embargo, es Aristóteles quien responde al problema de la arkhé como búsqueda en torno al fundamento de la totalidad de lo existente, con la noción de substancia (ousía) ${ }^{7}$ como un compuesto de materia y forma.

El problema de la arkhé, del que se ocuparon los primeros filósofos, plantea la inter-relación entre las cosas existentes y el hombre que las piensa, así como también entre el fundamento (ser $)^{8}$ y lo fundamentado (entes). Aquí se establece una relación crucial entre tres términos: ser-humano, entes y ser, constitutivos de lo real en cuanto tal, y la actividad que problematiza esta triple inter-relación es la filosofía, debido a que el serhumano es el único ser existente que puede preguntarse por el ser del ente. Así, la pregunta fundamental de la filosofía acaece, en el ser-humano, de este modo: ¿qué es el ser?, como así también ¿por qué hay entes y no más bien nada? Estas preguntas ponen en marcha a la filosofía y a la historia misma de Occidente. La inter-relación anteriormente expuesta es determinante para la historia, porque de acuerdo con la comprensión epocal que en

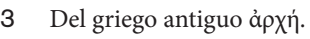

4 Del griego antiguo $\lambda o ́ \gamma o \varsigma$.

5 Hay que tener en cuenta que la relación que se vislumbra en este párrafo es tripartita: tenemos, en primer lugar, las cosas existentes (los entes); en segundo lugar, el fundamento (el ser), y por último, al ser-humano que piensa y expresa lo comprendido en esta relación, tema que abordaremos en el desarrollo del texto.

6 Previo a este modo de pensar tal búsqueda resultaba innecesaria dado que la realidad, en su totalidad, estaba fundada plenamente por lo mítico-religioso.

7 Del griego antiguo ov̉oía.

8 Del griego antiguo eĩvaı. 
el hombre acaezca de aquella relación, se manifestará un modo peculiar de comprender, habitar y aprehender el mundo, lo que constituirá a la historia como tal.

Ahora bien, cuando Aristóteles define al hombre como un ser dotado de razón, es decir, que su capacidad racional lo diferencia de los demás seres vivos, convierte en una exigencia racional que este dé cuenta de los primeros principios o las primeras causas (cfr. Aristóteles 74, 982 a), asentando, de este modo, las bases de la metafísica como ciencia y planteando así el escenario sobre el cual la filosofía se constituirá en metafísica. El dar razones de sus afirmaciones es propio de esta ciencia, que adopta la forma de demostración. Pero Aristóteles cae en la cuenta de que no todas las proposiciones la reclaman para sí o pueden serlo, puesto que caeríamos en una demostración circular de resolución indefinida, lo que destruiría la esencia misma de la demostración. Dado que la demostración absoluta es imposible, podemos, sin embargo, proceder a través de una más restringida, a partir de proposiciones privilegiadas que no requieren ser demostradas, porque estas proposiciones son absolutas, universales y necesarias; además, deben ser inmediatamente verdaderas, es decir, evidentes: "La metafísica se constituye como tal al adoptar los principios que han de guiar la reflexión y explicación del ente en cuanto ente y sus atributos esenciales" (Corti 43). Queda, así, fundada la metafísica como ciencia que estudia al ente en cuanto ente, es decir, lo que es en tanto que es y las propiedades que por sí le pertenecen. En este sentido, se piensa el ser en relación al fundamento de los entes.

Ahora bien, Heidegger muestra que la pregunta por el ser (sein) mismo constituye la primera y última tarea de la filosofía a lo largo de toda su historia. La exigencia de llegar a esta pregunta originaria tiene el aspecto de un retorno al pensamiento griego, lo que muestra, asimismo, que el significado de los términos esenciales de los primeros pensadores fue profundamente modificado por la filosofía posterior. Este hecho se acentuó con las traducciones latinas de palabras griegas, que, al ingresar a la cultura occidental, modificaron el pensamiento antiguo hasta tornarlo casi ininteligible con respecto a su originalidad.

Habíamos afirmado que la filosofía misma se constituye en cuanto tal como resultado del cuestionamiento que el ser-humano realiza con respecto a la totalidad de la realidad en la que está inmerso, cuyo preguntar filosófico propio se expresa en la pregunta: ¿por qué es, en general, el ente y no más bien la nada? (Heidegger, Introducción a la metafísica 39), como asimismo, ¿qué es el ser?, acaeciendo, de este modo, a una íntima relación entre ser y hombre, dado que el hombre es el que pregunta por el ser y el ser solamente puede ser señalado por el hombre. Cuando nos involucramos con el problema en cuestión e intentamos hoy contestar a estas preguntas, nos reencontramos, irremediablemente, con la misma dificultad que dio inicio a la filosofía en sentido propio, pero que ha producido, también, el desarrollo de lo que Heidegger llama "historia de la metafísica occidental". Ante la urgencia de la gravedad de aquel asunto que los primeros pensadores griegos supieron escuchar y señalar (dado que Parménides y Heráclito han señalado al ser sin salir del ámbito del ser mismo suponiendo la diferencia con lo ente), los filósofos posteriores se 
orientaron a referir que lo que tenemos delante es esto o aquello9. Es decir, respondieron con una determinación expresada en la proposición "S es $\mathrm{P}$ "10. Sucede, pues, que se dispone la respuesta al preguntar qué inicia la filosofía bajo una estructura lógica ${ }^{11}$ de pensamiento que lo determina, lo fija y, por ende, lo limita: el concepto. Ante la pregunta ¿qué es el ser?, se responde el ser es esto o aquello; la respuesta, en cuanto limitación categorial, adquiere el carácter de definición. En estos casos, y en cualquier otra definición que se pueda ofrecer, estamos respondiendo con un ente determinado, con algo determinado. Pero un ente es algo que es, pero no es el ser. Replantearnos esta pregunta es situarnos ante el asunto del pensar propio que inicia la filosofía en cuanto tal. Pero preguntar por el ser y contestar con un ente revela un extravío (Irre) (cfr. Heidegger, "Introducción a ¿Qué es metafísica?" y "La sentencia de Anaximandro"), que para Heidegger constituye el origen tanto de la filosofía como nos ha llegado a ser conocida (como metafísica), así como de la propia historia de Occidente (cfr. introducción de Leyte, Identidad y diferencia 14). Por ello, Heidegger señala: "Esto es lo que rige en la tradición desde el comienzo (Beginn) ${ }^{12}$, lo que está siempre por delante de ella, y con todo, sin ser pensado expresamente ${ }^{13}$ como lo que inicia (Anfang)" (Heidegger, Identidad y diferencia 111).

Heidegger sostiene que lo que en la tradición filosófica se ha dado en llamar principio de identidad, se ha adoptado como el pre-sub-puesto onto-lógico de todo pensar conceptual, implicado y dispuesto en la forma de comprender el verbo cópula en la proposición "S es P", y que, a su vez, tal principio ha quedado sin pensar y sin problematizar, instaurándose como determinación y límite del pensamiento. Ello produce el dominio tecno-científico por parte del hombre hacia lo real, fundando el poder tecnológico que da comienzo y desarrolla la historia occidental como onto-teo-logía ${ }^{14}$ (cfr. Heidegger, Identidad $y$ diferencia), en cuanto posibilita la objetivación de lo real. De este modo,

9 Con la expresión "primeros filósofos" nos estamos refiriendo a Heráclito y Parménides, y con la expresión "filósofos posteriores" a la tradición filosófica, desde Sócrates y Platón, hasta Nietzsche.

10 Una proposición es una relación de carácter atributivo entre términos, la cual tiene la propiedad de ser verdadera o falsa. La estructura de toda proposición es vincular o relacionar un término llamado sujeto con otro llamado predicado a través del verbo. De ahí la sigla $S$ es $P$. Lo que aquí está en cuestión no es ni el término sujeto ni el término predicado, sino qué comprendemos por la noción "es" que los vincula. La tradición filosófica adoptó como respuesta a este problema la conceptualización que Aristóteles señala en el libro Delta de la metafísica, "el ser se dice de muchas maneras", se dice, primariamente, de la sustancia y, secundariamente, de los accidentes (Aristóteles $\left.162,1003^{\mathrm{a}}\right)$.

11 La lógica es una ciencia formal que estudia los métodos y principios para diferenciar un razonamiento correcto de otro incorrecto y, a su vez, establecer las condiciones de la proposición, la definición y la inferencia correcta.

12 Para Heidegger hay una diferencia esencial entre comienzo (Beginn) e inicio (Anfang). Inicio hace referencia al planteo de la pregunta que da origen a la filosofía en cuanto tal: ¿qué es el ser?; en cambio, comienzo nombra el olvido de la diferencia ontológica que posibilita la historia de la metafísica y sus diferentes épocas. De este modo, comienzo nombra el instante cronológicamente primero, ya que lo en él mentado es lo temporalmente ordenado, tal es el objeto de la historia (Historie), que intenta aprehender desde la exactitud del cálculo tanto al comienzo como a lo devenido desde aquel primer instante. Frente a esto, el inicio es el espacio originario del que se nutre el acaecer de la historia acontecida (Geschichte), del cual se alimenta también a todo acontecer posterior (cfr. Heidegger, Identidad y diferencia 111).

13 La diferencia ontológica.

14 Estos conceptos son así comprendidos dentro de la historia de la metafísica. 
podemos afirmar que la filosofía nace y comienza ligada a un extravío (Irre), ya que preguntar ¿qué es el ser? y responder con un ente determinado devela un equívoco, donde la identidad, en tanto principio onto-lógico al que el pensamiento se subsume, se constituye en límite infranqueable para sí mismo. El pensar debe rendir cuentas al tribunal de la razón, que establece los límites y alcances de todo pensar. De este modo, la filosofía se disuelve en metafísica. Entonces, según Heidegger, al adoptar la identidad como supuesto, la filosofía extravía el camino iniciado por Parménides y Heráclito ${ }^{15}$, constituyéndose en metafísica; así pues, solo se podrá pensar lo ente y se dejará sin pensar al ser, olvidándose la diferencia entre ser y ente. ¿Qué significa pre-sub-puesto? Puesto significa algo que es instalado, afincado, afianzado, en un lugar. Sub significa que eso puesto es un soporte por debajo, es cimiento que sustenta toda la estructura. Por último, pre significa que eso puesto por debajo que cimienta toda la estructura es puesto de antemano quedando in-pensado ${ }^{16} \mathrm{y}$, por lo tanto, está a salvo de todo cuestionamiento, litigio y análisis por parte del pensamiento.

Antes de analizar qué mienta el principio de identidad, veamos cuál es el sentido de época en la historia de la metafísica para Heidegger, lo cual nos llevará a redefinir la noción de verdad. En la metafísica hay un destino histórico guiado por el ser mismo. El ser se manifiesta en el ente, pero se retiene a sí mismo en cuanto ser, puesto que solo aparece como ente, como algo que es, y en lo que es, se muestra la verdad del ente. En el ente solo hay una aparición: la de su verdad, la cual deja en sombras la revelación del ser. A este acontecimiento, en el que se detiene la aparición del ser presente en pos de la presencia de lo ente, Heidegger lo llama época: el exhibido ocultarse del ser. El ser se sustrae al desentrañarse en el ente y, de este modo, se retiene a sí mismo. El originario signo de esta retención está en la a-létheia. Al producirse el des-ocultamiento de todo ente, se funda el ocultamiento del ser. Pero cada época de la historia de la metafísica está pensada a partir de la experiencia del olvido del $\operatorname{ser}^{17}$. El olvido del ser, que se produce en la metafísica, deriva del ser mismo. Por eso, la metafísica está destinada a constituir, a través de los entes, las distintas épocas de la historia del ser. Es evidente, entonces, el nexo interior que une la metafísica con la historia, ya que esta supone el ocultamiento necesario del ser y aquella se define por su olvido. Pero la historia (Geschichte) es el proceso en el cual el ser ad-viene en el ente desocultándolo, pero ocultándose él mismo.

15 El pensar se inicia, según Heidegger, en la frase de Parménides relativa a la mismidad de pensar y ser; y en el modo en que Heráclito retiene la unidad de phýsis y lógos.

16 Lo no-pensado no se refiere a todo aquello que la filosofía dejó de pensar, o a los temas que quedaron marginados de la reflexión y del pensar conceptual, sino más bien a lo que aparece como olvidado en la historia del ser, en la metafísica, pero que, precisamente, por aparecer así, ha dado lugar a la misma metafísica. Lo in-pensado no fue olvidado al principio de esa historia, y por eso no es algo que hubiera que recuperar, sino que es lo que está presente en cada pensador en el modo de la ausencia.

17 Esta difícil concepción se halla en íntima conexión, como es evidente, con la idea de tiempo. Puesto que el ser acaece en el ente que lo oculta, es fundamento del acontecer o hacerse (Geschichte), es lo que, al temporalizarse, funda toda temporalidad. Hay, pues, una historia (Historie) óntica, abarcada por la ciencia histórica, y otra del ser, que corresponde al transcurso de la revelación del ser mismo y su destino histórico. Puesto que este se hace manifiesto en cuanto se abre temporalmente, por lo tanto, su verdad o des-ocultamiento constituirá el tiempo mismo. 
Entonces, para Heidegger, las distintas épocas históricas están configuradas por lo que llama "destino del ser"; ello refiere al significado que asume en el lenguaje la noción de ser en una época determinada, o en una civilización; sentido del que depende la aprehensión de la realidad en general que un grupo cultural determinado tiene para relacionarse entre sí y con el mundo que lo circunda. La historia de la metafísica occidental constituye una forma propia de lenguaje para expresar esa relación asentada, de modo general, en la estructura proposicional "S es P". De acuerdo a cómo se pre-comprenda al es, ello determinará la relación y el modo de aprehender lo real manifestado a través del lenguaje ${ }^{18}$. Es decir, que lo que está siempre en juego, en toda época, es el entre (zwischen) de la proposición, el es. Ello es lo que problematiza la pregunta ¿qué y por qué la diferencia? Pero en la historia de la metafísica, la respuesta a la cuestión es reducida a la identidad que el concepto mantiene consigo mismo.

En suma, la metafísica es aquel pensar propio de Occidente que busca determinar al ente en su ser. Su punto de partida está en los entes mismos, en lo finito, en lo limitado, en las cosas mismas. El ser-humano, en cuanto ser mortal, está entremedio de ellas y tropieza con ellas, en las dimensiones propias de su existencia: el espacio y el tiempo, lo que implica la apertura del mundo como mundo. Así, la metafísica se constituye como tal al configurar un modo propio de preguntar sobre los entes. Por un lado, la cuestión es ¿qué es el ser del ente?, esto es: preguntarse por el ente en cuanto tal, es decir, qué es en general lo que mienta al ente en cuanto tal. Esta pregunta apunta a la estructura ontológica del ente. Por otro lado, se cuestiona ¿por qué es el ente y no más bien la nada? Esta pregunta resalta el carácter contingente de todo ente mundano; pero, equívocamente, a lo largo de la historia, se ha asociado dicha pregunta con el ente último del que todo surge y del que todo depende. Esta interrogación apunta a la estructura teo-lógica del ente supremo. Por ello es que la metafísica occidental se ha constituido en íntima unión onto-teo-lógica. Es muy difícil explicar la procedencia de tal constitución, pero una de las hipótesis que podemos aventurar es la gran dimensionalidad que implica la noción del ser. La metafísica es aquella disciplina que teoriza sobre el ente en cuanto ente, en busca de su estructura general -ontología-, y teoría del ente supremo del cual dependen todos los demás entes -teología-. La doble configuración de la metafísica como onto-teo-logía presenta conexiones ${ }^{19}$ que no han sido problematizadas en sus raíces comunes. Cuestionarlas equivale a pensar lo in-pensado en la metafísica y esto implica, de algún modo, estar fuera de ella. Heidegger llama "historia de la metafísica" a la forma de pensar que desde Platón a Nietzsche se despliega como teoría general del ser del ente y como teoría del ente supremo (onto-teología), dado que se ha olvidado al ser mismo, a favor del ser como fundamento del ente. Así, la pregunta por el ser se ha transformado, desde el comienzo, en una pregunta por lo que tiene de general cada ente y por el ente del que dependen todos los demás, pero

18 En relación con la comprensión de la historia como destino del ser es que Heidegger interpreta a la filosofía de Nietzsche como consumación tecno-científica de la metafísica occidental.

19 Tal conexión es lo que en la tradición filosófica-metafísica se ha considerado como principio de identidad. 
acá aparece un extravío o enlace equívoco porque se identifica al ser con aquel ente que fundamenta y causa toda existencia ${ }^{20}$. Tal identificación es la que hace posible, a la vez, pensar al ser como fundamento. Al identificar al ser como fundamento de lo ente se olvida la diferencia en cuanto tal, esto es, la diferencia entre ser y ente. Aceptado esto, se abre el camino para que el ente supremo, y a través de la concatenación entre causas y efectos, se constituya en fundamento y, a la vez, en causa primera de todo lo existente. Ello constituye el olvido de la diferencia como diferencia-diferenciante.

El ser-humano, en su quehacer cotidiano y quizás sin ser consciente de ello, tanto en el lenguaje como en la relación que tiene con las cosas mismas en cuanto habita el mundo, comprende o, como diría Heidegger, tiene una pre-comprensión que se establece entre el ser y la nada, entre el ser y el devenir, entre el ser y la apariencia, y entre el ser y el pensar. Esto significa que, en el habla cotidiana, expresamos siempre una pre-comprensión del ser que implica co-pensarlo en el horizonte de la nada, del devenir, de la apariencia y del pensar. Pero lo decisivo dentro de este aspecto, y que Heidegger ha señalado lúcidamente, es que la metafísica se desarrolla como actividad que supone al pensamiento dentro del horizonte onto-teo-lógico, pero no convierte a la dimensión del ser mismo y a la relación que este tiene con lo ente en problema; es decir, no se pregunta ¿qué es la diferencia y por qué la diferencia? Solo se problematiza y se desarrolla la cuestión de lo ente. En Platón, por ejemplo, lo ente aparece como aspecto o idea cuya estabilidad y unidad hacen que permanezca idéntica a sí misma. Por el contrario, las cosas sensibles muestran una inestabilidad en tanto devienen, surgen y desaparecen; en tanto entes sensibles su ser consiste en participar o imitar a las ideas. En Aristóteles ello tiene el carácter de interpretación categorial de la ousía, como también la comprensión de la cosa como obra (ergon $)^{21}$ en el ámbito de la dýnamis ${ }^{22}$ y la energeia ${ }^{23}$. Ahora bien, este esquema o estructura que define a la metafísica onto-teo-lógicamente no puede ser atribuido absolutamente ni a Platón ni a Aristóteles; aunque Heidegger sostenga que en Aristóteles la metafísica se constituyó como tal, numerosos estudios han demostrado que ello es insostenible. Sin embargo, podemos afirmar que la metafísica se ha afianzado, de tal modo, conforme a la tradición medieval, a la asimilación y apropiación de la filosofía griega por el mundo cristiano y, fundamentalmente, a las discusiones escolásticas y a la relectura de Aristóteles en clave teológica. Para rastrear cómo se afianza la metafísica, habría que realizar un análisis exhaustivo de la historia interna de las ideas en esta época, pero cuyo fin no persigue este estudio. Ahora bien, a modo de indicaciones, podemos establecer cuatro oposiciones propias del modo de pensamiento metafísico: 1) cuando la investigación es guiada por la oposición entre el ser y la nada, lo que se pregunta es por el ente en cuanto tal; 2) cuando la oposición es entre el ser y el devenir, se pregunta por la relación existente entre lo uno y lo múltiple; 3) cuando la oposición se piensa entre el ser

20 Tal identificación es posible porque está supuesta y opera la lógica de la identidad.

21 Del griego antiguo $\dot{\varepsilon} \rho \omega \nu$.

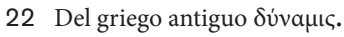

23 Del griego antiguo દ̉vé $\rho \gamma \varepsilon ı$. 
auténtico y el ser inauténtico, se pregunta por el ente supremo como criterio absoluto de ser, y 4) cuando la oposición es entre el ser y el pensar, se pregunta y tematiza por el estatus y la concepción de la verdad. Estos problemas guían el pensar filosófico en cuanto la metafísica es comprendida onto-teo-lógicamente, y corresponden a lo que en la tradición filosófica, tanto en la Época Antigua, como en la Medieval y la Moderna, se ha conceptualizado bajo la noción del ser en el horizonte de lo que se dio en llamar "trascendentales del ser", con matices diferentes en cada una de ellas: on, hen, agathon, alethes ${ }^{24}$; o ens, unum, bonnum y rerum (cfr. Fink 218). De este modo, queda evidenciada la lógica de oposición, que se instituye y guía a todo pensar filosófico dentro de la tradición metafísica, y que frente a la problematización y tematización de aquellas oposiciones, la filosofía resuelve reducir uno de los extremos al otro, esto es, identificar lo verdaderamente real con uno de los extremos de la oposición que se fundamenta sobre el otro extremo, el cual, a su vez, se yergue en cimiento de este. Entonces, en la filosofía antigua podemos decir, de modo general, que se reduce lo múltiple a lo uno (la idea en Platón; la sustancia en Aristóteles), de modo que el pensamiento metafísico opera categóricamente de acuerdo con una suerte de onto-logía objetiva inmanente; en el caso de la filosofía medieval, a la pregunta: ¿por qué lo creado?, la respuesta es categórica y reduccionista: "porque depende de su creador", en este caso, tendríamos una suerte de teo-logía objetiva trascendente. Por último, cuando la filosofía moderna se pregunta, de modo general, por la relación entre sujeto y objeto, podemos decir que se reduce lo representado a la representación, de manera que el pensamiento establece las condiciones de posibilidad de la objetividad del objeto. Por ello es que la metafísica se presenta, en la época moderna, como una suerte de onto-logía subjetiva trascendental ${ }^{25}$. Ahora bien, ¿qué sucede con nuestra época, la actual?, ¿cómo es comprendida tal relación de oposición? El desarrollo del texto tiende a problematizar esta cuestión determinante para situarnos y habitar el mundo en el siglo XXI.

Si bien, cabe destacar que nunca las generalizaciones son correctas, el fin que buscamos es demostrar que la lógica de oposición que adopta el pensamiento occidental es posibilitada a partir de pre-sub-poner el principio de identidad (no problematizado en la historia de la metafísica) y que, a su vez, impide pensar la diferencia-diferenciante entre el ser y lo ente. Entonces preguntamos: ¿qué es, cómo aparece y cómo se comprende, en la tradición filosófica occidental, el principio de identidad?

\section{B. El principio de identidad: la constitución del fundamento y la verdad}

En filosofía se llama ente a todo aquello que es y que existe de alguna manera, ya sean sensibles, como los entes físicos o los entes psíquicos; ideales, como los entes matemáticos

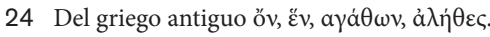

25 Recordemos que para Heidegger la metafísica y su historia se constituye en íntima unión onto-teo-lógica. Nosotros estamos mostrando el carácter distintivo y peculiar que cada época conlleva. 
y las esencias; y los axiológicos, como los valores morales. De todo esto puede predicarse: el término es. A lo que hace que estos entes sean, se lo llama ser. Cuando preguntamos, entonces, por el ser de los entes planteamos el asunto propio de la filosofía cuyo carácter es onto-lógico.

Ahora bien, en la tradición filosófica encontramos un sentido óntico y un sentido lógico del principio de identidad, pero ambos se han entremezclado y terminaron siendo aspectos de una misma concepción; es decir, cuando el ser-humano piensa lo real, lo nombra discursivamente, suponiéndolo. Ello es lo que enuncia la proposición "S es P", donde se comprende al es como fundamento de lo ente en tanto identidad onto-lógica. El principio de identidad afirma que "todo ente es idéntico a sí mismo". La fórmula usual del principio es expresada de la siguiente manera: $A=A^{26}$. Este principio es considerado la suprema ley lógica del pensar ${ }^{27}$. La tradición filosófica convirtió en principio de identidad los principios aristotélicos de no contradicción y tercero excluido; el primer principio señala que cualquiera sea el ente en cuestión no puede ser y no ser al mismo tiempo y bajo un mismo respecto, mientras que el segundo señala que todo ente es o no es; no es posible la formulación de una tercera posibilidad. Ambos principios fueron asociados a la frase en la que Parménides señala la mismidad entre ser y pensar, a saber, "ser y pensar son lo mismo" (Eggers y Juliá 436-8). Pues, ¿qué significa esta fórmula, leída desde la tradición metafísica? La fórmula indica la igualdad de una cosa consigo misma, es decir, la igualdad entre A y A, ens et ens. Siempre que tomamos a un ente como ente, lo estamos considerando desde la identidad consigo mismo. Siguiendo a Heidegger, cuando decimos lo mismo, por ejemplo una flor es una flor, se está expresando una tautología, no nos hace falta repetir dos veces la misma palabra para que algo pueda ser lo mismo, pero esto sí ocurre en una igualdad. Entonces, la fórmula $\mathrm{A}=\mathrm{A}$ habla de igualdad, por lo cual no se nombra a cada A como lo mismo. La identidad anunciada por Parménides no dice que todo ente sea igual a sí mismo, dado que identidad e igualdad no son lo mismo, pero nuestra tradición ha confundido ambos sentidos. La palabra identidad deriva del griego tó autó 28 , que significa "lo mismo"; comprendida así, identidad quiere decir mismidad y no igualdad. Tal fórmula encubre lo que, en su origen, la identidad anuncia. Este cambio de sentido (de mismidad a igualdad y unidad) en la comprensión de la identidad produce un extravío en el pensar occidental, claramente señalado por Heidegger, y constituye la historia de la metafísica, además de que disuelve la esencia de la filosofía relativa a problematizar la diferencia, en onto-teo-logía. A partir de ello, se piensa la triple relación

26 La identidad, en su sentido originario, es ontológica, pero nosotros recibimos tal principio de la tradición filosófica, en la que aquel sentido fue reemplazado por el lógico. Aquí, la lógica guía al pensamiento filosófico en tanto establece qué es digno de pensarse y qué no (cfr. Heidegger, “¿Qué es metafísica?”).

27 El principio de identidad no lo formula Aristóteles, pero él supone la auto-identidad de cada ente consigo mismo, sobre todo en la formulación canónica del principio de no contradicción. Estamos hablando, naturalmente, del principio de identidad de la llamada lógica de predicados, esto es, $(\mathrm{x})(\mathrm{x}=\mathrm{x})$, donde $\mathrm{x}$ es una variable de individuo. Igualmente, esto no está formulado de este modo en Aristóteles y menos aun aparece formulado en el corpus que una proposición es idéntica a otra proposición $(\mathrm{A}=\mathrm{A})$, donde la letra $\mathrm{A}$ es una variable proposicional.

28 Del griego antiguo tò aủtò. 
constitutiva de lo real y de la filosofía, esto es: ser-humano, entes y ser, presuponiendo el principio de identidad. Esto determina, en lo sucesivo, la objetivación de lo real a través del concepto y posibilitará la manipulación tecno-científica. Ahora bien, ¿qué expresa el principio de identidad?

Lo que expresa el principio de identidad, en la historia de la metafísica, es que la unidad de la identidad constituye un rasgo fundamental del ser de lo ente, y se constituye como supuesto de todo pensar en la medida en que es una ley que dice que a cada ente le corresponde la unidad e igualdad consigo mismo (cfr. Pöggeler 154). Igualdad y unidad pertenecen a todo ente en cuanto tal, siendo un rasgo fundamental del ser del ente. Si los rasgos fundamentales del ser son la unidad y la igualdad, estos rasgos son concebidos como fundamentos de todo lo ente (unificados por el principio de identidad), lo que posibilita su aparición y su permanente presencia en la unidad de la identidad de sí mismo.

La primera formulación de la noción de identidad aparece dentro del pensamiento occidental en el pasaje del fragmento B 2 del poema de Parménides que reza "tò gàr autò noein estín te kaì eînai"29, que Heidegger vierte al alemán como "Das Selbe nämlich ist Vernehmen (Denken) sowohl als auch Sein", y que traducimos a nuestra lengua hispana del siguiente modo: "Lo mismo es en efecto percibir (pensar) que ser". Reparemos en la cita; tó autó, que en griego significa "lo mismo", pero es comprendido bajo categorías onto-lógicas de la ciencia filosófica en su devenir histórico. Traducido al latín como "idem" es, de este modo, interpretado como "igualdad", en sentido lógico, y como unidad, en sentido óntico. Así, podemos observar que en la frase de Parménides, leída desde la tradición filosófica, opera un cambio radical de sentido, ya que se entendió que ser y pensar son idénticos y forman una unidad. El mensaje de Parménides, en sentido propio, fundador del pensamiento filosófico, se transforma, así, en principio de identidad, con lo que se da comienzo a la historia de la metafísica occidental. ¿Por qué? Porque se transformó totalmente el inicio del pensar. Si lo mismo, tó autó, en griego; idem, en latín; das Selbe, en alemán, se comprende como igualdad lógica y unidad onto-lógica, la frase de Parménides dice, por un lado, idénticos son ser y pensar, y por el otro, ser y pensar forman una unidad. En la proposición "S es P" se comprende al $e s^{30}$ como identidad y como unidad, es decir, como identidad onto-lógica. Al identificar al ser del ente en cuanto tal como fundamento de cada ente, como lo fundado, se olvida al ser mismo en cuanto a su diferencia ontológica originaria. Pero el ser fundamento que funda no es el ser, en su diferencia-diferenciante, con lo ente.

Ahora bien, la identidad, presupuesta en la metafísica, ubica en un lugar privilegiado a ciertas proposiciones (principios evidentes), que permiten un modo peculiar de acceso e inteligibilidad de lo real en cada época de la historia del ser. En el caso de la Época Antigua, el ser (como fundamento de lo ente) es comprendido como elemento determinante

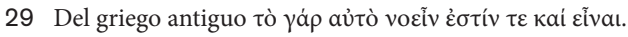

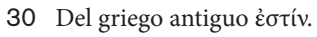


(principio evidente) con respecto al pensar: "El ser es", afirma Parménides. Dado que fuera del ser nada hay y solo es posible pensar lo que es, necesariamente el pensar tiene que identificarse con el ser. La verdad se presenta en cuanto adecuación (adaequatio) del pensamiento y lo enunciado en la proposición con respecto al ser. Así, ser y pensar son idénticos, en sentido lógico, y forman una unidad, en sentido óntico.

Por otro lado, en la Época Moderna, el pensar se determina a sí mismo (principio evidente) como elemento determinante con respecto al ser que, a su vez, implica la disposición de una nueva concepción de la verdad definida como certeza; certeza que tiene el yo-sujeto ante la objetividad del objeto (certeza de la representación). "Pienso, luego soy" ${ }^{\text {, }}$, afirma Descartes, dado que fuera del pensamiento nada hay, el ser, necesariamente, tiene que identificarse con el ser pensamiento. El pensamiento mismo garantiza para sí la certeza de ser. El pensar se presenta idéntico al ser, en cuanto conciencia de ser (lo pensado) y autoconciencia de sí (el pensamiento). La Época Moderna es configurada, de este modo, como identidad subjetiva. La identidad es comprendida entre la representación y lo representado. Si el rasgo fundamental del ser del ente es ser fundamento, y si el yo ocupa el lugar del ser como fundamento, entonces, este se constituye en fundamento de lo real efectivo, es decir, de todo lo ente en general en cuanto que es el ente privilegiado entre todos los entes restantes, porque satisface la nueva esencia de la verdad decidida en cuanto certeza:

No admitir jamás como verdadera cosa alguna sin conocer con evidencia que lo era; es decir, evitar cuidadosamente la precipitación y la prevención y no comprender, en mis juicios, nada más que lo que se presentase a mi espíritu tan clara y distintamente que no tuviese motivo alguno para ponerlo en duda (Descartes 95$)^{32}$.

Y si su fundamentar (representar claro y distinto) es cierto, entonces, todo representar es verdadero; y si todo representar es verdadero, todo lo que el sujeto-yo represente es real. Observamos, por lo tanto, que la identidad entre el fundamento y lo fundamentado es subjetiva porque la verdad del representar cierto depende del yo-sujeto. Descartes reinterpreta la noción de identidad mostrando una nueva esencia de la verdad en cuanto certeza, y abre el camino para que el yo-sujeto se constituya en ese ente privilegiado entre todos los demás. La identidad, en cuanto tal, queda sin cuestionar, impensada, y garantiza por sí y para sí la identidad sujeto-verdad-objeto. Pero en cuanto pre-sub-puesto, Des-

31 "Pero advertí enseguida que aun queriendo pensar, de ese modo, que todo es falso, era necesario que yo, que lo pensaba, fuese alguna cosa. Y al advertir que esta verdad -pienso, luego soy- era tan firme y segura que las suposiciones más extravagantes de los escépticos no eran capaces de conmoverla, juzgué que podía aceptarla sin escrúpulos como el primer principio de la filosofía que buscaba" (Descartes 108). Es el pensamiento el que afirma al ser, en donde descubrimos que pensar y ser se nos presentan idénticos. El pensar es fundamento que afirma al ser del hombre como substancia pensante. El pensamiento se presenta como fundamento, en tanto ser del ente.

32 Las notas distintivas de la verdad en cuanto certeza son la claridad y la distinción, pero, asimismo, requieren de un fundamento absoluto e indubitable que satisfaga esta nueva esencia de la verdad. La constitución del yo, en cuanto sujeto absoluto y fundamento del representar claro y distinto, es la que va a reclamar para sí la esencia de la verdad en cuanto certeza. 
cartes, con su duda metódica, no problematiza el principio de identidad, dado que este sostiene toda la fundamentación metafísica. Por lo tanto, en la metafísica cartesiana no se da un nuevo comienzo de la filosofía, sino que continúa su desarrollo abriendo una nueva época en su historia.

Recordemos también que la consumación de lo que Heidegger llama metafísica de la subjetividad solo comienza con Descartes, pero falta muchísimo para que el camino abierto se haya llevado a cabo. Para ello, debemos señalar el rumbo metafísico que el proceso consumará en la filosofía de Hegel. Si el yo pienso es concebido como principio, lo verdadero es la substancia en sí, que deviene sujeto para sí, como saber de sí. Lo verdadero es el todo, la substancia devenida sujeto es la unidad sujeto-objeto, es decir, el saber absoluto. Aquí estamos ante la dialéctica, donde no es ya lógica formal, sino que es la ciencia en la que método y contenido van unidos. La forma está unida al principio. De este modo se explica la multiplicidad de entes a partir de la identidad del pensar con el ser. Pero aquí también la multiplicidad es fenómeno, porque al identificar la verdad con lo absoluto y lo absoluto con la unidad, solo reduciendo lo múltiple a la unidad estaremos en posesión de la verdad (cfr. Corti 44).

Nosotros afirmamos, entonces, que este modo de pensar rige todo el pensamiento occidental, en cuanto se ha constituido como historia de la metafísica. Consecuentemente, en la relación con los entes nos encontramos determinados por la identidad. Si no oyéramos la determinación de la identidad, lo ente nunca conseguiría aparecer en su ser. Tampoco se daría ninguna ciencia; pues, si no se le garantiza la identidad (permanente presencia) de su objeto (objetividad de la representación), la ciencia no podría oír el llamado hacia la dominación. A partir de la garantía que proporciona la identidad, las investigaciones se aseguran el éxito de su dominio. Es decir, si a la ciencia no le estuviera garantizada de antemano la unidad de su objeto, ella no podría controlar, prever y manipular lo real (Heidegger, Identidad y diferencia 67-9). La propia frase de Parménides es interpretada, a partir de la identidad metafísica, de la siguiente manera: al tomar a un ente en cuanto ente, se está tomando al ente en su ser o en su verdad. El "en cuanto que" del giro "ente en cuanto ente" remite a la verdad de lo ente, pero exige, al mismo tiempo, un pensar. Si lo ente no fuera pensado como lo que es, no podría ponerse en relieve como el ente que es y no podría llegar a su ser, o a su verdad. Entonces, al pensar lo ente como convertible con lo verdadero, la metafísica ha dado por sentada la identidad entre ser y pensar (cfr. Pöggeler 154). De este modo, podemos desprender un segundo sentido. Al representar la identidad como un rasgo del ser, este, en consecuencia, es dotado de significado, de una determinación, a saber, la de ser fundamento. Con ello, el ser es sustituido por un ente, aunque continuará conservando el nombre de ser. Pero el ser no es ningún significado, y por eso no tiene propiedades. La identidad no es propiedad alguna del ser. Pero teniendo al ser como ese ente idéntico a sí mismo, y fundamento de lo ente en general, está abierta la posibilidad para que el hombre, mediante las ciencias, pueda manejar, organizar, clasificar, producir y destruir. Con esta comprensión, estamos entendiendo al ser como algo técnico, en el sentido de que es nuestra obra. Cuando le damos el significado de técnica, se vuelve a 
tomar al ser como un ente y, por ello, no podemos atender a que, en esta situación técnica, es el hombre quien resulta un ente, una cosa, a quien le viene impuesto lo técnico (de antemano) bajo la forma de asegurar todo sometiéndolo a un cálculo y a un plan que ha de extender ilimitadamente. La persistencia de comprender, metafísicamente, a la técnica, es decir, signada por la identidad, conduce precisamente a la extensión de su dominio. La ampliación del dominio es la extensión de la destrucción de todos los objetos naturales o históricos. El hombre mismo se autosacrifica industrializando su vida para seguir pensando, paradójicamente, que él es el amo de la técnica. En este sentido, nuestra historia es metafísica porque hemos realizado un mundo de acuerdo con el ideal de objetividad, esto es, asegurar al ente en la objetividad del concepto (permanente presencia) para poder manipularlo, lo que permite la expansión de la tecno-ciencia a escala planetaria.

Para finalizar, desde la perspectiva de la identidad, ya sea que se afirme como principio al ser-Época Antigua-, ya sea que se afirme al pensar como principio -Época Moderna-, la explicación y relación con los entes múltiples va a resultar como realidad aparente para los antiguos y fenoménica para los modernos. Así, lo múltiple no es real, es apariencia, manifestación de lo que en verdad no es. Solo es verdadero que el ser es o el pensar es. Los múltiples entes son la negación de la unidad verdadera. Esto explica la comprensión epocal de la triple relación constitutiva de la filosofía entre ser, hombres y entes, y expresa, por lo tanto, la estructura lógica disyuntiva sobre la que se ha constituido la metafísica occidental.

\section{Más allá del fundamento y la verdad. La recepción deleuzia- na de la filosofía de Nietzsche. "Activo-reactivo": una ontología de la diferencia de fuerzas}

Es sabido el gran interés que la obra de Nietzsche despierta en el pensamiento deleuziano, a la vez que lo potencia. Ello se debe a dos cuestiones relevantes: en primer lugar, la filosofía de Nietzsche le permite a Deleuze vislumbrar los límites y el dogmatismo que asume la tradición filosófica al ocuparse de la cuestión del fundamento como último peldaño o escalón al que el pensamiento, a través de la deducción o la dialéctica, pudiera llegar, y así se pudiera conocer la esencia del hombre, de la vida, el espíritu, lo absoluto o de cualquier ámbito del mundo. En Nietzsche, Deleuze encuentra las armas que le permiten hacer frente a esta cuestión; luchar contra la concepción del ser como totalidad, como fundamento de lo ente en general y como el fundamento más elevado por sobre todos los entes, al modo teológico propio de la tradición filosófica. Pero esta cuestión trae aparejada el problema de la verdad, el concepto de la verdad. Ella también queda cuestionada junto con la noción de ser, sea de cualquier modo que se la quiera comprender (sea como adecuación, correspondencia o representación). De este modo, Deleuze indaga críticamente en la concepción clásica del pensamiento como búsqueda y amor a la verdad. La idea central que Deleuze encuentra en el pensamiento nietzscheano para combatirla es 
que el pensamiento no es una acción autónoma, nunca se piensa por sí mismo (al modo cartesiano), sino que el pensamiento está siempre condicionado por relaciones de fuerzas tanto extrínsecas como intrínsecas al mismo. Entonces, la pregunta ¿qué es la verdad?, ¿qué es lo verdadero?, debe ser reemplazada por ¿qué quiere quien afirma tal cosa como la verdad o lo verdadero? Desde la lucha y el camino que emprende Deleuze al respecto podemos adelantar que pensar depende siempre de fuerzas que se apoderan del pensamiento. Por ello, Deleuze reivindica, desde la filosofía nietzscheana, una nueva práctica filosófica como praxis que mienta el sentido de las fuerzas que constituyen un cuerpo y establece su forma de valorar evaluando las inter-relaciones y las conexiones que entre las diferentes fuerzas se establecen.

Deleuze, por su parte, sostiene que la filosofía debe entenderse como una crítica positiva en el sentido de que ella implica creatividad afirmando que "el problema crítico es el valor de los valores, la valoración de la que procede su valor, o sea, el problema de su creación" ${ }^{33}$ (Deleuze, Nietzsche y la filosofía 7). Este problema solo se puede evaluar a partir del elemento diferencial (la voluntad de poder), que es el elemento determinante de toda valoración dado que muestra la cualidad de la fuerza, activo-reactivo, y es a la vez elemento crítico y creador. El problema crítico es doble: el valor de los valores (el sentido) y la valoración de la que procede su valor (la voluntad), es decir, los modos de existencia, diferenciales, jerárquicos, creadores de valores (lo alto y lo bajo, lo noble y lo vil):

[...] así entendida, la crítica es al mismo tiempo lo más positivo. El elemento diferencial no es crítica del valor de los valores, sin ser también el elemento positivo de una creación. Por este motivo la crítica no ha sido jamás concebida por Nietzsche como una reacción, sino como una acción. Nietzsche opone la actividad de la crítica a la venganza, al rencor o al resentimiento (Deleuze, Nietzsche y la filosofía 9).

Este doble movimiento de la crítica deviene así en genealogía activa, positiva, creativa. Pero a continuación afirma Deleuze:

Nunca encontraremos el sentido de algo (fenómeno humano, biológico o incluso físico), si no sabemos cuál es la fuerza que se apropia de la cosa, que la explota, que se apodera de ella o se expresa en ella. Un fenómeno no es una apariencia ni tampoco una aparición, sino un signo, un síntoma que encuentra su sentido en una fuerza actual (Nietzsche y la filosofía 10).

Así como el desarrollo del problema del valor supone un nuevo método (genealogía), también el desarrollo del problema del sentido requiere de una teoría de las fuerzas. La historia de una cosa, cualquiera que esta sea, supone una sucesión de fuerzas que se apoderan de ella, la constituyen y coexisten en ella para apoderársela. Un mismo fenómeno cambia su sentido de acuerdo con la fuerza que se apodere de él. Pero siempre hay una 
pluralidad de sentido, una constelación de sentido. El sentido es una noción compleja: en primer lugar implica siempre relaciones plurales. Una constelación es un sistema abierto. En un sistema cerrado hay leyes que gobiernan el movimiento y las relaciones entre los elementos, aun cuando el sistema sea dinámico y variable. En una constelación eso no es posible, porque no se puede abarcar la totalidad y porque su conocimiento es siempre provisorio. La constelación incluye tanto las relaciones temporales como las espaciales. Así, la historia es la variación de esos sentidos en estas relaciones y se puede apreciar haciendo una hermenéutica de las fuerzas que en cada momento se apropian de un fenómeno o de un ser y que le confieren un sentido actual o que le fueron dando diferentes sentidos en el tiempo. En definitiva, todo acontecimiento ${ }^{34}$ tiene múltiples sentidos. Por ende, los conceptos de esencia/apariencia, idea/opinión, valor en sílaplicación tienen que ser abandonados y reemplazados por fuerzas/síntomas, fenómenos/ sentidos. Ningún fenómeno tiene sentido en sí mismo, sino a partir de las fuerzas que se apoderan de él. Además, esos sentidos nunca son eternos o permanentes, sino que son siempre inestables. Hay que pensar en una dinámica de las fuerzas. No se trata de un sistema cerrado de fuerzas, sino de un sistema inestable. Al dominar un fenómeno, la fuerza le da un sentido, una dirección. El significado más simple de sentido es dirección. Deleuze, a partir de la filosofía de Nietzsche, está desarrollando una teoría general de la fuerza que no se restringe a las relaciones humanas ni sociales, tampoco a lo orgánico, vital o biológico. Las fuerzas son relaciones entre fenómenos. Las relaciones entre fuerzas ni siquiera suponen un sujeto. Aquí Nietzsche se muestra como un heredero de la tradición iluminista: Kant ya había impreso el giro al pensamiento por el cual se deja de poner el acento en el conocimiento para centralizarlo en la acción, en la moral. Después de él, la primacía de la acción se desarrollará cada vez más con Fichte, Schelling, Hegel, la filosofía del idealismo alemán, Marx y la filosofía de la praxis. Nietzsche es heredero de esta tradición que deja de pensar en términos de cosas o de esencias para pensar en términos de acción, de fuerzas (o, como la va a llamar más adelante, de voluntad). En síntesis, por un lado, el sentido es siempre múltiple porque está constituido por una pluralidad de fuerzas que lo definen pero, también, diferentes respecto a otras fuerzas; por otro lado, el sentido nunca es absoluto sino que cambia cuando cambian las fuerzas que se apoderan de él.

34 El concepto de "acontecimiento" es central en el pensamiento deleuziano. Se opone a la concepción cristiana y dialéctica de la historia, que la considera sujeta a una legalidad necesaria y a una teleología que encamina los hechos hacia un fin único en el que se consuma todo el desarrollo. El concepto de "acontecimiento" supone una relación contingente de las relaciones de fuerza en la historia. ¿Cómo se produce un acontecimiento si no es como resultado de un movimiento dialéctico? Cuando se habla de "acontecimiento" hay que pensar en una multiplicidad de fuerzas (aunque los tipos de fuerzas puedan reducirse a lo alto y lo bajo). Hay acontecimientos que resultan de una conjunción de fuerzas activas y creativas, como en Mayo del 68. Los acontecimientos de este tipo no se caracterizan por su duración sino por los efectos múltiples que generan. (En un reportaje a Mario Benedetti divulgado en un programa sobre este autor uruguayo en Canal Encuentro, decía que para su generación el acontecimiento había sido la Revolución cubana y no Mayo del 68, que no había tenido consecuencias significativas para los sudamericanos.) Los grandes acontecimientos no están precedidos por causas que permitan preverlos con anterioridad, sino que pueden resultar de situaciones mínimas, banales o imperceptibles, las cuales pueden vincularse con el "efecto mariposa". 
Retomemos el otro problema de la genealogía: el valor. Deleuze afirma que "la genealogía no solo interpreta sino también valora" (Nietzsche y la filosofía 14):

Cualquier fuerza se halla pues en una relación esencial con otra fuerza. El ser de la fuerza es el plural; sería completamente absurdo pensar la fuerza en singular. Una fuerza es dominación, pero también objeto sobre el que se ejerce una dominación. Una pluralidad de fuerzas actuando y sufriendo a distancia, siendo la distancia el elemento diferencial comprendido en cada fuerza y gracias al cual cada una se relaciona con las demás (Nietzsche y la filosofía 14).

El elemento diferencial (la voluntad que es una fuerza relacionada con otra fuerza) permite evaluar y caracterizar la diferencia en el origen como la cualidad de la vida y solo hay dos tipos de vida: lo afirmativo y lo negativo, lo alto y lo bajo, la acción y la reacción. La pregunta que supone el elemento diferencial con respecto a las fuerzas es: ¿es activa o es reactiva?, ¿es afirmativa o es negativa?, ¿ es alta o es baja? La diferencia implica siempre actividad (o re-actividad), movimiento (o resistencia), relación (mando u obediencia) y generación (creación o decadencia). Porque el problema de la filosofía como crítica genealógica es la relación que se establece entre una voluntad que ordena y otra que obedece:

Que cualquier fuerza se relaciona con otra, sea para obedecer: sea para mandar, he aquí lo que nos encamina hacia el origen: el origen es la diferencia en el origen, la diferencia en el origen es la jerarquía, es decir la relación de una fuerza dominante con una fuerza dominada, de una voluntad obedecida con una voluntad obediente (Deleuze, Nietzsche y la filosofía 16).

Por ello afirma Deleuze que el verdadero problema de la genealogía es la jerarquía ${ }^{35}$, y ella es inseparable de la diferencia y del origen. La genealogía tiene como tarea el problema del sentido y del valor y su mutua relación dado que "el sentido de una cosa es la relación entre esta cosa y la fuerza que la posee, el valor de una cosa es la jerarquía de las fuerzas que se expresan en la cosa en tanto que fenómeno complejo" (Nietzsche y la filosofía 16). Entonces las fuerzas pueden ser evaluadas cualitativamente o cuantitativamente. Desde el punto de vista de la cualidad o diferencia, las fuerzas pueden ser altas o bajas, nobles o viles, dominantes o dominadas. Desde el punto de vista de la cantidad, las fuerzas pueden ser fuertes o débiles, afirmativas o negativas. Así lo explica Deleuze:

Nietzsche llama voluntad de poder al elemento genealógico de la fuerza. Genealógico quiere decir diferencial y genético. La voluntad de poder es el elemento diferencial de las fuerzas, es decir, el elemento de producción de la diferencia de cantidad entre dos

35 Deleuze afirma que "la jerarquía tiene dos sentidos en Nietzsche. Significa, en primer lugar, la diferencia de las fuerzas activas y reactivas, la superioridad de las fuerzas activas sobre las reactivas [...] Pero jerarquía designa también el triunfo de las fuerzas reactivas, el contagio de las fuerzas reactivas y la organización compleja que viene detrás, donde los débiles han vencido, donde los fuertes son contaminados, donde el esclavo que no ha dejado de ser esclavo prevalece sobre un señor que ha dejado de serlo: el reino de la ley y de la virtud. Y en este segundo sentido, la moral y la religión aún son teorías de la jerarquía" (Nietzsche y la filosofía 88). 
o varias fuerzas supuestas en relación. La voluntad de poder es el elemento genético de la fuerza, es decir el elemento de producción de la cualidad que pertenece a cada fuerza en esta relación. La voluntad de poder como principio no suprime el azar, al contrario, lo implica (Nietzsche y la filosofía 77).

El azar siempre pone en relación al menos dos fuerzas diferentes. La voluntad de poder es el elemento diferencial y genealógico de la fuerza, es decir, ella determina la relación de una fuerza con otra fuerza al tiempo que produce la cualidad de las mismas, a la vez que se manifiesta como un poder de ser afectado ya sea por fuerzas superiores o por fuerzas inferiores:

La voluntad de poder es el elemento del que se desprenden a un tiempo la diferencia de cantidad de las fuerzas en relación, y la cualidad que, en esta relación, corresponde a cada fuerza. Aquí revela su naturaleza la voluntad de poder: es el principio de la síntesis de las fuerzas (Nietzsche y la filosofía 74).

Por ello la voluntad de poder nunca se puede separar de la fuerza sea esta cualquiera de sus cualidades y cantidades. La voluntad es al mismo tiempo determinada y determinante, cualificada y cualificante (cfr. Deleuze, Nietzsche y la filosofía 90). Tengamos en cuenta que la voluntad de poder no es la misma fuerza, hay que diferenciar la voluntad de la fuerza, pero la voluntad de poder no es exterior a la fuerza, es la fuerza misma, su afectividad. Esto podemos aclararlo al preguntar ¿quién quiere? No se puede responder la fuerza, porque no es la fuerza quien quiere, sino la voluntad es quien quiere y ello no pude ser alienado ni delegado. Sin el elemento interno de la voluntad toda fuerza sería indeterminada. "La voluntad de poder, pues, se suma a la fuerza, pero como elemento diferencial y genético, como elemento interno de su producción" (Deleuze, Nietzsche y la filosofía 75). Deleuze también afirma que la voluntad de poder no es el ser ni tampoco el devenir. "La voluntad de poder se manifiesta como la sensibilidad de la fuerza; el elemento diferencial de las fuerzas se manifiesta como su sensibilidad diferencial" (Nietzsche y la filosofía 91). Es decir, es el poder de afectar y ser afectado, ello remite a que ella se muestra como sensibilidad, sensación, afectividad.

Deleuze se pregunta entonces:

¿Qué es el cuerpo? Solemos definirlo diciendo que es un campo de fuerzas, un medio nutritivo disputado por una pluralidad de fuerzas. Porque, de hecho, no hay "medio", no hay campo de fuerzas o de batalla. No hay cantidad de realidad, cualquier realidad ya es cantidad de fuerza. Únicamente cantidades de fuerza, "en relación de tensión" unas con otras. Cualquier fuerza se halla en relación con otras, para obedecer o para mandar. Lo que define a un cuerpo es esta relación entre fuerzas dominantes y fuerzas dominadas. Cualquier relación de fuerzas constituye un cuerpo: químico, biológico, social, político. Dos fuerzas cualesquiera, desiguales, constituyen un cuerpo a partir del momento en que entran en relación: por eso el cuerpo es siempre fruto del azar, en el sentido nietzscheano, y aparece siempre como la cosa más "sorprendente", mucho más sorprendente realmente que la conciencia y el espíritu. Pero el azar, relación de la 
fuerza con la fuerza, es también la esencia de la fuerza; no nos preguntaremos, pues, cómo nace un cuerpo vivo, ya que todo cuerpo es viviente como producto "arbitrario" de las fuerzas que lo componen. El cuerpo es un fenómeno múltiple, al estar compuesto por una pluralidad ${ }^{36}$ de fuerzas irreductibles; su unidad es la de un fenómeno múltiple, “unidad de dominación”. En un cuerpo, las fuerzas dominantes o superiores se llaman activas, las fuerzas inferiores o dominadas, reactivas. Activo y reactivo son precisamente las cualidades originales, que expresan la relación de la fuerza con la fuerza. Porque las fuerzas que entran en relación no poseen una cantidad, sin que al mismo tiempo cada una deje de tener la calidad que corresponde a su diferencia de cantidad como tal. Se llamará jerarquía a esta diferencia de las fuerzas cualificadas, conforme a su cantidad: fuerzas activas y reactivas (Nietzsche y la filosofía 60-1).

No hay que entender el campo o el medio como algo previo a las fuerzas. Cuerpo no es lo que ocupa un lugar en el espacio. No se trata de un lugar o de un escenario previamente constituido donde la relación de fuerzas tendría lugar. Son las relaciones de fuerzas las que crean el medio o el escenario. Las fuerzas crean el ámbito que necesitan. Cuando se da prioridad al campo o al medio, la resolución del conflicto entre las fuerzas se traslada al contexto de la relación, a la totalidad que contendría a las fuerzas (a la manera del estructural-funcionalismo). El escenario o la totalidad es un resultado parcial, contingente y provisorio de las relaciones entre las fuerzas. Definición de cuerpo: allí donde hay al menos dos fuerzas en relación. ¿De qué ámbito? ¿De qué tipo? De cualquier tipo, de cualquier ámbito: químico, físico, social, político, etcétera. En física se ha diferenciado entre los cuerpos y la energía, las ondas. Para Deleuze no hay escisión: cuerpo es energía, es una relación de fuerzas/energías.

Un cuerpo no se define por lo que es, sino por lo que puede; esto ya es un cuantum de fuerzas en relación, afirma Deleuze citando a Spinoza. No podemos definir de antemano lo que un cuerpo puede, de lo que un cuerpo es capaz, dado que depende de las relaciones de fuerzas que lo constituyen, de la capacidad de afectar y ser afectado, de multiplicar y crear conexiones y relaciones nuevas, de aumentar o no su capacidad de actuar. Pero en un cuerpo, sostiene Deleuze, solo se actualiza una porción de su poder. Un cuerpo deviene junto a otros cuerpos produciendo, afirmando relaciones, encuentros y conexiones; afirmando diferencialmente su poder, su ritmo singular de cambio. Un cuerpo es un proceso abierto y en formación continua, oscilante, que des-estructura toda forma a priori de fundamentación. Por todo ello es que afirma Deleuze, "no sabemos de lo que un cuerpo es capaz" (Nietzsche y la filosofía 62). Un cuerpo es un flujo constante de fuerzas diferentes en relación dis-funcional con otros cuerpos, pero siempre es una totalidad inacabada e incompleta. Por ello no es posible delimitar, definir, identificar de antemano qué es un cuerpo. El cuerpo se sustrae a los límites del pensamiento representativo, dado que un cuerpo es siempre

36 Se introduce aquí el concepto deleuziano de "multiplicidad". Contra Platón, lo real no remite a lo uno, ni siquiera a la dualidad, sino a una multiplicidad. No se parte de la identidad sino de la diferencia. 
posibilidad de realizar diferencias siempre nuevas, pero un cuerpo siempre es más de lo que realiza, es un campo de fuerzas generativas y productivas, como se dijo más arriba, actualizándose sin agotar su poder de cambio. Ahora bien, la diferencia entre las fuerzas se llama "jerarquía". Todo cuerpo es una relación de fuerzas desiguales, es decir, jerárquicas: Las fuerzas inferiores se definen como reactivas: no pierden nada de su fuerza, de su cantidad de fuerza, la ejercen asegurando los mecanismos y las finalidades ${ }^{37}$, ocupándose de las condiciones de vida y de las funciones, las tareas de conservación, de adaptación y de utilidad. Este es el punto de partida del concepto de reacción (Deleuze, Nietzsche y la filosofía 61).

Las fuerzas reactivas se definen por su función o fin: conservar, adaptar, utilizar. Las fuerzas reactivas están siempre reguladas: siguen una regla, una ley, un límite, un impedimento. Lo reactivo se define desde el otro término de la relación, es decir, desde lo activo. Por eso las fuerzas reactivas parten siempre del límite, del impedimento, de lo que no se puede. Pero Deleuze advierte:

Indudablemente caracterizar a estas fuerzas activas es más difícil. Ya que, por naturaleza, escapan a la conciencia ${ }^{38}$ : "La gran actividad principal es inconsciente" ${ }^{39}$. La conciencia expresa solamente la relación de algunas fuerzas reactivas con las fuerzas activas que las dominan. La conciencia es esencialmente reactiva; por eso no sabemos lo que puede un cuerpo, de qué actividad es capaz (Nietzsche y la filosofía 62).

La conciencia es vista como un síntoma del cuerpo y no como su fundamento. Tomarla como síntoma es tomarla como efecto y no como causa. El síntoma no tiene que ser confundido con la causa. La conciencia es una mera superficie: aquella parte del cuerpo que se ve afectada por el mundo. Es un epifenómeno. Lo que le interesa remarcar a Deleuze es que la relación de la conciencia con lo exterior es siempre una relación entre dos fuerzas desiguales: una inferior y otra superior. La misma relación supone dos valoraciones, de acuerdo con la perspectiva de las fuerzas dominadas o a la de las fuerzas dominantes. La primera es la moral de los esclavos; la segunda es la moral de los señores. Los esclavos valoran partiendo del límite, de la ley, de lo que regula o impide. La conciencia parte de lo que no puede. Los señores valoran partiendo de lo que pueden. La valoración no está en la fuerza en sí misma sino en la relación que una fuerza establece con otras. Por eso, el concepto de fuerza no sustituye el concepto de substancia. Para Aristóteles la relación es un accidente de la substancia; para Nietzsche la relación de fuerzas es lo que constituye el cuerpo. La conciencia siempre está en relación con lo no-consciente o con lo inconsciente.

37 La discusión entre mecanismo y finalidad es una falsa discusión, ya que ambos son posibilidades de las fuerzas reactivas, ambos son reactivos. La verdadera discusión es entre lo reactivo y lo activo.

38 Lo activo se identifica con lo inconsciente. Por eso no puede conocerse o comprenderse desde la conciencia. Las fuerzas activas escapan a la conciencia.

39 Nietzsche, La voluntad de poder 227 (cit. en Deleuze). 
Ese inconsciente es el cuerpo. Lo inconsciente es activo, creativo, productivo, transformador. Por ello afirma Deleuze que "la conciencia: testimonia únicamente 'la formación de un cuerpo superior"' (Nietzsche y la filosofía 60):

“QQué es lo que es activo? Tender al poder”. Apropiarse, apoderarse, subyugar, dominar, son los rasgos de la fuerza activa. Apropiarse quiere decir imponer formas, crear formas explotando las circunstancias (Nietzsche y la filosofía 63).

Las fuerzas activas sostienen siempre una tensión, una lucha, un antagonismo. Tienden a, se dirigen a... Pero, aquello a lo que se dirigen no es una substancia o un ser. Se dirigen al poder. Lo que quiere la fuerza es más fuerza. Lo que quiere el poder es más poder. El poder no tiene que ser pensado como una cosa o un ser, ni como una propiedad de las cosas o de los sujetos, ni como una facultad, ni como el lugar que ocupan ciertos sujetos. "Tender al poder" es desarrollar ese poder, es desarrollar las fuerzas, es crear más fuerza. Lo que caracteriza a lo activo es la capacidad de crear, pero no de crear cosas sino de crearse a sí mismo, de potenciarse a sí mismo. Detrás de la concepción spinoziana ("no sabemos lo que un cuerpo puede") está la concepción hobbesiana, y detrás de la concepción hobbesiana están las concepciones de Maquiavelo y Tucídides. Todos estos autores piensan el poder como fuerza y no como substancia o como ser. De allí que para caracterizar a las fuerzas activas utilicen verbos y no adjetivos: apropiarse, apoderarse, subyugar. Activo son las fuerzas positivas, las fuerzas superiores, las fuerzas creativas y transformadoras. En la primera parte de este capítulo se llamó “dionisíaco" a este tipo de fuerzas. Es el poder de transformación, es pura actividad. Afirma Deleuze:

Pero cada vez que señalamos así la nobleza de la acción y su superioridad frente a la reacción, no debemos olvidar que la reacción designa un tipo de fuerzas del mismo modo que la acción: sencillamente, las reacciones no pueden captarse, ni comprenderse científicamente como fuerzas, si no las relacionamos con las fuerzas superiores que son precisamente de otro tipo. Reactivo es una cualidad original de la fuerza, pero que solo puede ser interpretada como tal en relación con lo activo, a partir de lo activo (Nietzsche y la filosofía 63).

Se trata de fuerzas en relación, no de relaciones entre cosas o propiedades de una substancia o un sujeto. Deleuze tiene presente la teoría del poder de Foucault (cfr. Deleuze, Foucault 49 y ss.): el poder no es una propiedad, no es un lugar, no es una cosa, no es un atributo. No se tiene poder; se ejerce poder, se actúa. Toda fuerza es un ejercicio del poder. Toda fuerza es, por definición, fuerza. No existe una fuerza carente de fuerza. Una fuerza activa es aquella que hace todo lo que puede, que lleva su fuerza al límite de lo que puede. Una fuerza reactiva nunca hace todo lo que puede, no lleva la fuerza al límite sino que parte del límite. Foucault no habla de fuerzas reactivas sino de resistencias. No hay poder sin resistencia. Se trata siempre de una relación, el poder es relación. Pero una incapacidad de lo reactivo para comprenderse a sí mismo más allá de su propio horizonte, que es el horizonte de la reacción, de la supervivencia. 
Ahora bien, estas fuerzas pueden ser evaluadas cuantitativamente, es decir, qué cantidad de poder hay en cada una de ellas, pero a su vez, pueden ser evaluadas cualitativamente ${ }^{40}$, es decir, de acuerdo con la diferencia de cantidad de fuerza, por eso afirma Deleuze "activo y reactivo son las cualidades de la fuerza" (Nietzsche y la filosofía 63). La diferencia de cantidad de fuerza es la esencia de toda fuerza. Toda cuantificación supone una valoración previa, una perspectiva valorativa implícita. Lo cuantitativo supone siempre una valoración cualitativa. "Si una fuerza no es separable de su cantidad, tampoco lo es de las restantes fuerzas con las que se halla relacionada. La cantidad en sí no es, pues, separable de la diferencia de cantidad" (Nietzsche y la filosofía 65). No se trata de dos formas contrapuestas de ordenar la realidad. La relación cualitativa de las fuerzas se desprende de las diferencias de cantidad. Los cuerpos son relaciones de fuerzas diferentes. Es la diferencia entre esas fuerzas lo que constituye la cualidad. La diferencia entre las cantidades no es cuantitativa sino cualitativa. No hay que pensar la diferencia entre las cantidades, cuantitativamente, abstractamente. Una fuerza solo se puede caracterizar por la relación, nunca en sí. Un cuerpo no es en sí noble o plebeyo, superior o inferior. Solo es noble o plebeyo en relación con otras fuerzas. La cualidad de las fuerzas no es una característica esencial de una cosa o substancia, es una relación que se cualifica de diferente manera de acuerdo con el otro término con el que se relaciona. Además aparece aquí una tesis central en la interpretación de Deleuze: no hay posibilidad de que se den dos fuerzas iguales. Es imposible eliminar las diferencias. Toda postura democrática, igualitaria, equivalencial es imposible. Para Deleuze, este es el sueño de las fuerzas reactivas. El problema no es la igualación de las fuerzas sino la reactivación de las fuerzas, que las fuerzas activas se conviertan en reactivas. El problema es lo que Nietzsche llamó nihilismo ${ }^{41}$.

En definitiva, contra los dualismos metafísicos apariencia/realidad, sensible/inteligible, etc., y la pretensión filosófica de llegar a través de un método a fundamentos últimos y verdades absolutas, Deleuze, mediante la filosofía de Nietzsche, propone una nueva praxis filosófica caracterizada como crítica genealógica, cuyos elementos decisivos son las nociones de sentido y valor que permiten evaluar las fuerzas en juego que se apoderan y conforman un cuerpo; de allí la relevancia genealógica de las preguntas: ¿qué quiere quien pretende establecer tal o cual verdad como absoluta y universal?, ¿qué fuerzas están detrás de ella?, porque para Nietzsche y Deleuze el pensamiento está siempre condicionado y determinado por relaciones de fuerzas, como ya hemos expuesto. La voluntad de poder es la que determina

40 Se plantea aquí un problema de larga data (la relación entre lo cuantitativo y lo cualitativo): se había planteado ya en la Lógica de Hegel y se discutió largamente en la tradición dialéctica desde Marx hasta Lenin.

41 "Según Nietzsche, el nihilismo es el lógico punto final de la filosofía occidental. La filosofía comienza con un proyecto de vida del ascetismo: el renunciar al deseo por algún mundo más alto o mejor (como el mundo de la verdad). Nos imaginamos un mundo más verdadero y mejor más allá de apariencias. Cuando fallamos en comprender aquel mundo verdadero nos caemos en la desesperación o el nihilismo, ya que hemos perdido aquel mundo más alto que nosotros nunca tuvimos. La consecuencia es el resentimiento. Todavía sentimos la pérdida de algún mundo más alto o mejor, y entonces nos imaginamos culpables, castigados o excluidos. Esto alcanza su culminación con el cristianismo donde somos permanentemente culpables en un mundo irredimiblemente caído. Para Nietzsche, la respuesta apropiada a esta caída en el nihilismo, la decadencia y el resentimiento no consiste en encontrar otra base de verdad, sino en abandonar nuestra esclavitud a la verdad. Tenemos que tener la fuerza y el coraje para vivir con este mundo aquí y ahora" (Colebrook 19). 
la fuerza y, por ende, da sentido, como elemento diferenciador. El sentido y el valor derivan de la voluntad de poder como relación diferencial de fuerzas. La voluntad de poder es así principio de la síntesis de fuerzas, que no subsume al modo dialéctico sino que afirma la diferencia al establecer jerarquías y cualificar a las fuerzas. Pero para que esta síntesis pueda realizarse se requiere de otro elemento relevante de la filosofía nietzscheana: el eterno retorno.

\section{Conclusión. La inmanencia. "El eterno retorno de la diferencia": una filosofía del devenir y lo múltiple}

El ser es comprendido por Deleuze como devenir de diferencia de fuerzas intensivas que se muestran y fluyen sobre un plano de consistencia. Ella es una diferencia que se rehúsa a toda conceptualización, especificación o limitación categorial. Aquí lo diferente se relaciona con lo diferente sin que pueda ser reducido a la identidad que opera en toda lógica de oposición. Esta es una diferencia móvil, que potencia y crea lo diferente, en cuanto diferente. Desde esta consideración sostiene Deleuze: “Todo lo que ocurre y aparece es correlativo de órdenes diferenciales: diferencias de nivel, de temperatura, de presión, de tensión, de potencia, diferencia de intensidad" (Deleuze, Diferencia y repetición 110). Estas diferencias tienen como elemento decisivo la intensidad: puro movimiento diferencial de fuerzas que se multiplican al infinito. Esto implica, a su vez, concebir la diferencia como pura positividad, lo que sugiere un proceso de permanente diferenciación, sin puntos de referencia o fundamentos últimos. Esta diferencia de fuerzas intensivas no puede ser definida o reducida desde una instancia exterior a ella, porque no hay exterior, lo que hay (el devenir) es diferencia. Esto es lo que llamamos "plano de consistencia" ${ }^{42}$, necesario para quebrantar los límites fijos que operan en la lógica de oposición metafísica. Consecuentemente, nos vemos obligados a des-fundamentar al sujeto y al objeto de su carácter trascendental y, a su vez, a dejar de pensar la diferencia a partir de un fundamento organizador. Desde la consideración del ser como devenir que diferencia activamente, el movimiento es flujo caótico, abierto, que des-fundamenta lo real. Pero ¿qué es la consistencia? La consistencia es el campo de fuerzas generativas y productivas que, constantemente, se actualizan en multiplicidades sin agotar su poder de cambio e impidiendo toda fundamentación. El plano de inmanencia o plano de consistencia es un todo ilimitado que se presenta siempre abierto pero que no totaliza sus partes en una unidad superior y absoluta dado que este plano mienta un sistema de coordenadas, de diferentes dimensiones y orientaciones, que producen constantemente conexiones que renuevan, a la vez, la totalidad del plano. El

42 Debemos aclarar que el plano de inmanencia o plano de consistencia no refiere a un concepto porque eso implicaría que los demás conceptos del plano sean totalizados o fundamentados por esta suerte de concepto superior, universal, absoluto y necesario al que se podría llegar a través de una deducción (propia de la tradición filosófica), lo que permitiría, en definitiva, el cierre total del campo. Así estaríamos nuevamente ante la presencia de un fundamento absoluto al modo onto-teo-lógico de la metafísica occidental; pero ello es justamente lo que combate la filosofía deleuziana. 
plano de inmanencia o consistencia es un plano que consta de dos caras: una comprende al ser (en tanto devenir), la otra refiere al pensamiento (el concepto). El concepto expresa las líneas de fuerzas y tensiones, los límites y las variaciones que constituyen al plano. Ello implica que no haya esencias trascendentes sino entrecruzamientos (encuentros y desencuentros, conexiones y desconexiones) de fuerzas. El concepto es una singularidad que sintetiza intensidades diferenciales y no abstracciones. Él es una meseta estratificada de múltiples dimensiones, nunca cerrado, y de conexiones virtualmente infinitas. En el concepto no hay totalizaciones universales o trascendentales, sino conexiones o series conjuntivas (y...y...y...y). Recordemos que para Deleuze pensar es crear-conectar conceptos y este es el movimiento propio en donde se produce la actividad filosófica; pero el plano no preexiste a los conceptos sino que a la vez que se crean los conceptos, las conexiones intensivas, se constituye el plano como receptáculo conceptual, que es el medio para toda creación y conexión posible. En definitiva, el pensamiento se ex-pone en el plano a la vez que experimenta creando conceptos. Esto significa que hay simultáneamente pensamiento (sentido) y ser (voluntad), y que, por un lado, se distribuye (el plano) como realidad y, por otro, se interpreta como sentido-pensamiento. Es decir, el pensamiento es inseparable del ser y el ser mismo es inseparable del devenir de la vida:

\footnotetext{
Un pensamiento que fuese hasta el final de lo que puede la vida, un pensamiento que llevase a la vida hasta el final de lo que puede. En lugar de un conocimiento que se opone a la vida, establecer un pensamiento que afirmaría la vida. La vida sería la fuerza activa del pensamiento, pero el pensamiento el poder afirmativo de la vida [...] Pensar significaría: descubrir, inventar nuevas posibilidades de vida (Deleuze, Nietzsche y la filosofía 115).
}

Conforme a la interpretación que Deleuze hace de Nietzsche, pensar es inventar nuevas posibilidades de vida, nuevas formas de sentido. Como hemos analizado en el apartado anterior, hay formas de vida que la exaltan y potencian, y otras formas que la aprisionan y des-potencian. En la inmanencia de la vida, en sus fuerzas, es que se sitúa el elemento que permite evaluar las diferentes formas de vida y pensamiento. No hay verdades absolutas, más allá del criterio que reside en la vida misma, sea esta noble o vil. Son estas fuerzas vitales las que permiten evaluar una vida como noble, fuerte, creadora o mezquina: llena de resentimiento y envidia. Sostener la inmanencia de la vida y del pensamiento implica rechazar necesariamente los fundamentos absolutos y las verdades universales. La inmanencia solo es inmanente a sí misma y a su propio devenir infinito. El peligro que ha acechado y acecha a la inmanencia de la vida es atribuir esta a alguna cosa, al espíritu, a la substancia, etcétera. Ello implica la constitución de universales abstractos o trascendentales propios de la tradición filosófica que se apropian del movimiento, de la inmanencia de la vida, que lo detienen y atrapan para ponerlo a disposición (objetividad del concepto). Detener el movimiento implica negar el devenir de la vida. La inmanencia de la vida refiere a la potencia con la que el ser se alza contra la nada instituyendo al devenir mismo como la actividad inmanente al ser. Así, Mengue define la inmanencia 
como "el encuentro de múltiples dimensiones o líneas de fuerza que se entrecruzan sin que una se eleve para cumplir el rol de unidad trascendente. La inmanencia reconduce al pluralismo" (Mengue 72). De este modo, la realidad (el mundo) aparece sobre un plano inmanente de múltiples dimensiones, constituidas, ellas, de diferentes líneas o relaciones de fuerza: líneas de despliegue o transformación (líneas de fuga), o líneas de reposo o estabilización (estratos o segmentos) ${ }^{43}$. La filosofía crea conceptos, sostiene Deleuze, esto es, experimentar para liberar las fuerzas vitales de todo aquello que tienda a conservarla y aprisionarla, porque la vida es devenir, flujo que siempre retorna.

Pero debemos preguntarnos, ¿cuál es el ser del devenir? Deleuze nos da la respuesta "Retornar es el ser de lo que deviene. Retornar es el ser del mismo devenir, el ser que se afirma en el devenir. El eterno retorno como ley del devenir" (Nietzsche y la filosofía 39), y en su obra sobre Nietzsche afirma también:

El eterno retorno, según Nietzsche, no es de ningún modo un pensamiento de lo idéntico, sino un pensamiento sintético, pensamiento de lo absolutamente diferente que reclama un principio nuevo fuera de la ciencia. Este principio es el de la reproducción de lo diverso como tal, el de la repetición de la diferencia (Nietzsche y la filosofía 69).

De este modo, Deleuze comprende al retorno como repetición pero no como repetición de lo mismo, de lo idéntico, sino que la repetición es de lo diferente de la diferencia, esto es, repetición de la posibilidad de relaciones, conexiones de fuerzas y multiplicidades siempre nuevas y diferentes. No es el ser el que retorna, el que vuelve, sino que es el propio retornar el que constituye al ser en cuanto se afirma en el devenir, y ello sucede eternamente. "No vuelve lo uno, sino que el propio volver es lo uno que se afirma en lo diverso o en lo múltiple" (Nietzsche y la filosofía 72):

El eterno retorno no es la permanencia del mismo, el estado del equilibrio ni la morada de lo idéntico. En el eterno retorno, no es lo mismo o lo uno que retornan, sino que el propio retorno es lo uno que se dice únicamente de lo diverso y de lo que difiere (Nietzsche y la filosofía 69).

El eterno retorno introduce en el pensamiento deleuziano, mediante la filosofía nietzscheana, la noción de tiempo y le brinda una importancia capital al instante. Escuchemos sus palabras al respecto:

[...] el eterno retorno debe pensarse como una síntesis: síntesis del tiempo y sus dimensiones, síntesis de lo diverso y de su reproducción, síntesis del devenir y del ser que se afirma en el devenir, síntesis de la doble afirmación (Nietzsche y la filosofía 72).

Es decir, que el retornar mismo es el que sintetiza pasado, presente y futuro en el instante como plena afirmación del ser que en su retornar difiere produciendo la múltiple

43 De este modo, la genealogía se convierte en una cartografía o diagrama para Deleuze: estudio de las líneas, sus caminos, sus movimientos sobre el plano. 
dimensionalidad de multiplicidades y al plano de inmanencia mismo a un mismo tiempo y de un solo golpe, de una sola tirada de dados, poniendo al azar como único principio del devenir.

A partir de la noción de eterno retorno, entonces, se aborda definitivamente desde la filosofía al tiempo en su dinamismo constitutivo y se acaba con las nociones estáticas y abstractas de pasado, presente y futuro. Asimismo, lo que retorna es la diferencia, esto implica que no hay ser, ni unidad fundamental, ni identidades de antemano. El mundo es un constante fluir de diferencias intensivas. El eterno retorno es la potencia del ser del devenir. En definitiva, lo que retorna es siempre lo que difiere. ¿Qué comprende, entonces, Deleuze por diferencia?

Aparece aquí una nueva ontología donde el ser es concebido como diferencia de diferencia, en cuanto que la diferencia es remitida a otras diferencias y no ya a la identidad como principio totalizador; en este sentido, la diferencia debe ser considerada desde tres perspectivas: diferencial, diferenciante y diferenciada. La primera refiere a la esencia del ser, pero no a su esencia abstracta, sino que refiere al ser en cuanto a su estado productivo, es decir, en su estado de potencia absoluta. La segunda muestra el estado tenso o intensivo de la diferencia, considerada en tanto conectada y ligada a otras diferencias; es aquella que hace que de la plena potencialidad (cfr. Gallego, "Prefacio a un libro necesario", en Mengue, nota 9,16) se genere, produzca y potencie lo virtual. Por último, en tercer lugar, la diferencia diferenciada refiere a la dimensión donde las diferencias ligadas se integran por regiones, es decir, donde la ligazón de las diferencias resuelve momentáneamente su constitutiva tensión alcanzando una estabilidad o actualidad provisoria que permite diferenciar unos simulacros ${ }^{44}$ de otros (cfr. Gallego, "Prefacio a un libro necesario", en Mengue, nota 9, 16). De este modo, desde este contexto ontológico que tiende a darle movilidad al ser, y que concibe al ser como devenir y haciendo del ser, el ser del devenir, lo real es lo mutable y la realidad el resultado de la mutabilidad decidida por y en el seno de la diferencia considerada desde los tres elementos expuestos.

Sin embargo, todo ello queda, al momento de pensarlo y expresarlo, reducido a las categorías propias de nuestras lenguas occidentales, constituidas sobre la lógica de la identidad. Como afirmamos arriba, nuestras lenguas (occidentales) son lenguas metafísicas, lo que sugiere que aquellas apresan al devenir y la multiplicidad en estructuras estables para ponerlas a disponibilidad técnica. En este sentido, cabe aclarar que al decir el ser es diferencia o el ser es devenir estaríamos volviendo a pensar de acuerdo con la estructura de pensamiento propia de la metafísica occidental, porque en aquellas proposiciones se está identificando al ser con un ente determinado (sea este ente cualquiera) conforme a la lógica de la identidad, por eso hemos optado por el genitivo para expresar y problematizar

44 Fernando Gallego afirma que la noción de simulacro no refiere a cierta falta de realidad de lo real, sino que la noción de simulacro sirve para poner a un lado las contiendas metafísicas sobre las nociones de cosa, ente y objeto; de este modo, el simulacro refiere a la verdad de la realidad en un triple sentido "1) porque se diferencia respecto de otros seres, 2) porque resulta diferenciado en el ser, 3) porque es, en sí mismo, bien una diferencia, bien la integración de un cierto complejo de diferencias mutuamente ligadas" (Gallego, "Prefacio a un libro necesario", en Mengue, nota 9,17$)$. 
la diferencia, con sentencias como el ser del devenir, o la diferencia de diferencia, dado que en estos casos está presente tanto la significación objetiva del genitivo como la subjetiva. De este modo, se le otorga movilidad al lenguaje y evitamos referir la diferencia a algún centro unificador, fundamentante o totalizador. Con ello, la diferencia resulta móvil y logra fugarse por medio de la lógica de oposición metafísica. ¿A qué refiere Deleuze con medio? Es aquello que no tiene principio ni fin. El medio no es centro en el espacio, ni el pasado, presente o futuro en el tiempo. Aquí no estamos hablando ni de evolución ni de historia. Una línea que pasa por medio de las oposiciones metafísicas supone un acontecimiento (línea de fuga). Por ello la fundamentación metafísica resulta inapropiada para comprender la inmanencia de la vida.

Para Deleuze la filosofía de la diferencia debe ser caracterizada como rizomática (cfr. Deleuze y Guattari). Los sentidos, simbolizados por los rizomas, crecen y proliferan por todos lados, sin justificaciones últimas que permitan prever dónde crecerá el próximo rizoma, ya que siempre proliferan en medio o entre la maleza; ni en el centro justificador ni en la periferia justificada de la lógica metafísica, sino por medio o entre las oposiciones metafísicas. El entre de lo múltiple supone una constante tensión entre lo mismo y lo otro, entre el azar y la necesidad; ello impide el aseguramiento total de lo real dentro de categorías objetivadoras. Por otro lado, la noción de entre permite la creación de sentidos, admitiendo que no hay arkhé fundamental y última cuyo carácter de verdad sea incuestionable. Pensar en el medio es como caminar entre las ruinas del edificio de la metafísica, reconociendo que la existencia tiene carácter trágico y, de este modo, no es posible la consideración de que lo diferente deba ser lo manipulable, objetivable y disponible. Recordemos que, con la categoría de disponibilidad, el sujeto moderno pensó la relación con lo real convirtiéndola en material disponible, categoría que presupone la identidad.

Problematizar la diferencia, a su vez, requiere experienciar la apertura del devenir, en la cual los acontecimientos se dan y se hacen perceptibles en su arraigo originario, que podemos nombrar como Dionisos (junto a Nietzsche y Deleuze) refiriendo a la comprensión del ser como diferencia-diferenciante que difiere de todo ente, pero que a su vez es posibilidad de todo ente, ello es, una fuerza eventualizante que se alza sobre la nada configurando distintos horizontes históricos, y que en su fluir por medio de las oposiciones los constituye en cuanto tal, pero los excede a la vez. En este sentido, las filosofías de Nietzsche y Deleuze son evidentemente contrastantes con la lógica de oposición que decide un fundamento absoluto en el que todo ente es fundamentado. El pensar por medio de las oposiciones metafísicas no tiende a encerrar al pensamiento en la objetividad del concepto, sino que abre un movimiento originario que en su función creativa y repetitiva hace acontecer y fluir nuevos mundos, instituye nuevos sentidos, nuevos acontecimientos. De este modo, estos pensadores se sitúan y dislocan la tradición metafísica de pensamiento. Este situarse en el medio de la metafísica permite una auténtica y siempre nueva reflexión filosófica cuyo movimiento es la libertad que deviene en la posibilidad de generar siempre nuevos sentidos históricos. Ello linda con lo que algunos filósofos contemporáneos, como Heidegger, Gadamer y Vattimo, entre otros, denominan hermenéutica ontológica, con- 
siderando a la interpretación como rasgo esencial de la existencia humana y como base para la crítica de la metafísica occidental, cuyo apoyo lo encuentran también en Nietzsche cuando afirma que no hay hechos, sino solo interpretaciones.

\section{Referencias}

Aristóteles. Metafísica. Trad. T. Calvo Martínez. Madrid: Gredos, 1998. Medio impreso. Colebrook, Claire. Gilles Deleuze. Londres-Nueva York: Routledge, 2002. Medio impreso. Corti, Enrique. Pensamiento y Realidad 12 (1985). 39-52. Medio impreso.

Deleuze, Gilles. Foucault. Buenos Aires: Paidós, 1986. Medio impreso.

---. Nietzsche y la filosofía. Barcelona: Anagrama, 1987. Medio impreso.

---. Diferencia y repetición. Madrid: Júcar, 1998. Medio impreso.

Deleuze, Gilles y Félix Guattari. Rizoma. Barcelona: Pre-Textos, 2003. Medio impreso.

Descartes, René. Discurso del método. Trad. R. Frondizi. Madrid: Alianza, 1999. Medio impreso.

Eggers Lan, Conrado y Victoria E. Juliá. Los filósofos presocráticos. Madrid: Gredos, 1994. Medio impreso.

Fink, Eugen. La filosofía de Nietzsche. Madrid: Alianza, 2000. Medio impreso.

Heidegger, Martin. Introducción a la metafísica. Trad. E. Estiú. Buenos Aires: Nova, 1969. Medio impreso.

---. Identidad y diferencia. Trad. H. Cortés y A. Leyte. Barcelona: Anthropos, 1990. Medio impreso.

---. "La sentencia de Anaximandro". Caminos de bosque. Madrid: Alianza, 1998. 239-277. Medio impreso.

---. “Introducción a ¿Qué es metafísica?”. Hitos. Madrid: Alianza, 2000. 299-312. Medio impreso.

Mengue, Philippe. Deleuze o el sistema de lo múltiple. Buenos Aires: Las cuarenta, 2008. Medio impreso.

Pöggeler, Otto. El camino del pensar de Martin Heidegger. Trad. F. Duque. Madrid: Alianza, 1986. Medio impreso. 